\title{
Chemical reactivity of hypervalent silicon compounds: The local hard and soft acids and bases principle viewpoint
}

\author{
FRANCISCO MÉNDEZ,* MARÍA DE L ROMERO and JOSÉ L GAZQUEZ \\ Departamento de Química, División de Ciencias Básicas e Ingeniería, Universidad Autónoma \\ Metropolitana-Iztapalapa, A.P. 55-534, México, D.F. 09340, México \\ e-mail: fm@xanum.uam.mx
}

\begin{abstract}
The silicon atom may increase its coordination number to values greater than four, to form pentacoordinated compounds. It has been observed experimentally that, in general, pentacoordinated compounds show greater reactivity than tetracoordinated compounds. In this work, density functional theory is used to calculate the global softness and the condensed softness of the silicon atom for $\mathrm{SiH}_{n} \mathrm{~F}_{4-n}$ and $\mathrm{SiH}_{n} \mathrm{~F}_{5-n}^{1-}$. The values obtained show that the global and condensed softness are greater in the pentacoordinated compounds than in the tetracoordinated compounds, a result that explains the enhanced reactivity. If the results are analysed through a local version of the hard and soft acids and bases principle, it is possible to suggest that in nucleophilic substitution reactions, soft nucleophiles preferably react with $\mathrm{SiH}_{n} \mathrm{~F}_{5-n}^{1-}$, and hard nucleophiles with $\mathrm{SiH}_{n} \mathrm{~F}_{4-n}$.
\end{abstract}

Keywords. Density functional theory; hard and soft acid and bases principle; hypervalent silicon compounds.

\section{Introduction}

The silicon atom may increase its coordination number to values greater than four, to form pentacoordinated compounds. ${ }^{1}$ It has been observed, experimentally, that, in general, pentacoordinated compounds show greater reactivity than tetracoordinated compounds. ${ }^{2 a}$ The first explanations of this behaviour attributed the enhanced reactivity to the pentavalent silicon atom, by noting that its positive character increases when the coordination increases. ${ }^{2 b}$ However, later on, Deiters and Holmes ${ }^{3}$ performed ab-initio calculations (HF/6$31+\mathrm{G}^{*}$ level) that led them to conclude that the enhanced reactivity is associated with an increase in the leaving group ability of the reactive ligand, and not with a significant change in the positive character of the silicon atom accompanying increased coordination at silicon.

The object of the present work is to make use of the hard and soft acids and bases (HSAB) principle ${ }^{4-9}$ and of its local version, ${ }^{10-12}$ and density functional theory (DFT) $)^{13,14}$ to analyze the global behaviour of hypervalent silicon compounds, and the role of the silicon atom in the reactivity of tetra and pentacoordinated species in nucleophilic substitution reactions. That is, rather than studying the leaving group

$\overline{\text { *For correspondence }}$ ability of the ligand and the charge of the silicon atom, we will focus on the global softness, ${ }^{13,15}$ and on the softness of the silicon atom in the molecule ${ }^{10}$ to rationalize the inherent reactivity of these chemical species. Such procedure has already been used to explain some aspects of the inherent reactivity of several molecules. ${ }^{16}$ Thus, in the present work we will discuss first the basic aspects of the local HSAB principle (§2), and then we will present results for $\mathrm{SiH}_{n} \mathrm{~F}_{4-n}$ and $\mathrm{SiHnF}_{5-n}^{1-}(\S 3)$.

\section{Global and local HSAB principles}

The HSAB principle, ${ }^{8,9}$ has been interpreted as the result of two opposing tendencies, one related to the charge transfer process, and the other one related to the reshuffling of the electronic density. This interpretation is the result of making the assumption that the interaction energy between two chemical species $\mathrm{A}$ and $\mathrm{B}$, may be divided into two steps which can be taken as happening in succession, that is

$$
\Delta E_{\text {int }}=\Delta E_{\mathrm{v}}+\Delta E_{\mu},
$$

where

$$
\Delta E_{\mathrm{v}}=\frac{-\left(\mu_{\mathrm{A}}-\mu_{\mathrm{B}}\right)^{2}\left(S_{\mathrm{A}} S_{\mathrm{B}}\right)}{2\left(S_{\mathrm{A}}+S_{\mathrm{B}}\right)},
$$




$$
\Delta E_{\mu}=-\frac{\lambda}{2\left(S_{\mathrm{A}}+S_{\mathrm{B}}\right)} .
$$

$\mu_{\mathrm{A}}$ and $\mu_{\mathrm{B}}$ are the chemical potential of A and B, $S_{\mathrm{A}}$ and $S_{\mathrm{B}}$ are their global softness, and $\lambda$ is a constant ${ }^{11,17}$ related to an "effective number of valence electrons" that participate in the interaction between $\mathrm{A}$ and $\mathrm{B}$.

The first step, $\Delta E_{\mathrm{v}}$, corresponds to the charge transfer process between $\mathrm{A}$ and $\mathrm{B}$ arising from the chemical potential equalization principle ${ }^{18}$ at constant external potential $v(\mathbf{r})$. The second step, $\Delta E_{\mu}$ corresponds to a reshuffling of the charge distribution, and it is basically a manifestation of the maximum hardness principle ${ }^{16 a}$ and it takes place at constant chemical potential $\mu$.

Through this procedure it has been possible to establish a local version of the HSAB principle by assuming that these tendencies are dominated by the local properties rather than by the global properties of the molecule. ${ }^{10-12}$ Thus, in general analysis of the inherent chemical reactivity of the sites of a given species $\mathrm{A}$ and $\mathrm{B}$, it has been shown that the interaction energy between two species $\mathrm{A}$ and $\mathrm{B}$, at the $k$ th and $l$ th atomic sites of $\mathrm{A}$ and $\mathrm{B}$ is given approximately by

$$
\Delta E_{\text {int }}=-\frac{\left(\mu_{\mathrm{A}}-\mu_{\mathrm{B}}\right)^{2}\left(S_{A k} S_{B 1}\right)}{2\left(S_{A k}+S_{B 1}\right)}-\frac{\lambda}{2\left(S_{A k}+S_{B 1}\right)},
$$

where $S_{A k}$ and $S_{B l}$ are the condensed softness of the $k$ th and $l$ th atoms in A and B respectively.

The condensed softness, or the softness of an atom in a molecule, may be derived through the chemical potential equalization principle that leads to define the Fukui function of the $k$ th atom in a molecule $\mathrm{A}$ with $N_{A}$ electrons, in the form, ${ }^{10}$

$$
f_{A k}^{+}=q_{A k}\left(N_{\mathrm{A}}+1\right)-q_{A k}\left(N_{A}\right),
$$

for nucleophilic attack,

$$
f_{A k}^{-}=q_{A k}\left(N_{\mathrm{A}}\right)-q_{A k}\left(N_{\mathrm{A}}-1\right),
$$

for electrophilic attack,

where $q_{A k}$ is the gross of the $k$ th atom in the molecule A, and it may be determined by several procedures. ${ }^{19,20}$ With these definitions the condensed softness becomes

$$
S_{A k}^{+}=S_{A}^{+} f_{A k}^{+}, \quad \text { for nucleophilic attack, }
$$

$$
S_{A k}^{-}=S_{A}^{-} f_{A k}^{-}, \quad \text { for electrophilic attack, }
$$

while the condensed hardness, or the hardness of an atom in a molecule is given by

$$
\eta_{A k}^{ \pm}=1 / S_{A k}^{ \pm} .
$$

The condensed softness satisfies the sum rule because $\sum_{k=1}^{K} f_{A k}^{ \pm}=1$, where $K$ is the total number of atoms in $\mathrm{A}$,

$$
\sum_{k=1}^{K} S_{A k}^{ \pm}=S_{A}^{ \pm}
$$

Now, according to (4), among two sites in A, each characterized by its own value of $S_{A k}$, when $S_{B l}$ is large, there is a greater stabilization when the interaction occurs at the site with the greater value of $S_{A k}$. However, when $S_{B l}$ is small, there is a greater stabilization when the interaction occurs at the site with the smallest value of $S_{A k}$. These results seem to imply that the statement "soft likes soft" and "hard likes hard" may be extended to a local level, and that although the softest atom in a molecule $\mathrm{A}$ is, in general, the most reactive site, there may be other sites, not as soft, that may become the most reactive sites, depending on the atomic softness of the reacting molecule B.

\section{Results}

In order to analyze the role of the silicon atom in the reactivity of tetra- and pentacoordinated species in nucleophilic substitution reactions, in the context of the local HSAB principle, one needs to calculate the condensed softness of the silicon atom by (7). This situation implies that one may perform ab-initio calculations to obtain the charges for the reference molecule $q_{A k}\left(N_{\mathrm{A}}\right)$ and its corresponding anion $q_{A k}\left(N_{\mathrm{A}}+1\right)$ at the minimum of the potential energy surface of the reference molecule. However, because of the difficulties associated with the SCF procedure for the anions of the molecules studied in this work, we also estimate the values of the global and condensed softness through a simpler procedure.

First, one may note that if the relaxation effects associated with the addition of charge are neglected, then $^{7}$

$$
S_{\mathrm{A}}=\left(\varepsilon_{\mathrm{A}}^{\mathrm{L}}-\varepsilon_{\mathrm{A}}^{\mathrm{H}}\right)^{-1},
$$


n $\mathrm{SiH}_{\mathbf{n}} \mathbf{F}_{4-\mathrm{n}}$

0<smiles>[3H][Si]([3H])(F)F</smiles>

1<smiles>F[Si](F)(F)F</smiles>

2<smiles>[1H][Si]([1H])([1H])F</smiles>

3<smiles></smiles><smiles>[1H][1H]</smiles>

4<smiles>F[Si](F)(F)F</smiles>

a<smiles>FC(F)F</smiles><smiles></smiles>

a<smiles>[1H]CF</smiles>

$\mathrm{SiH}_{\mathbf{n}} \mathrm{F}_{5-\mathrm{n}}{ }^{1-}$<smiles>F[Si](F)(F)(F)F</smiles><smiles>F[Si](F)(F)F</smiles><smiles>F[Si](F)(F)F</smiles><smiles></smiles><smiles></smiles>

ae<smiles>[1H][SiH3]</smiles>

5<smiles>[1H][1H]</smiles>

Figure 1. Tetra- and pentacoordinated silicon species; $\mathrm{SiH}_{n} \mathrm{~F}_{4-n}(0<n<4)$ and $\mathrm{SiH}_{n} \mathrm{~F}_{5-n}^{1-}(0<n<5)$; $a=$ apical and $e=$ equatorial.

where $\varepsilon_{\mathrm{A}}^{\mathrm{L}}$ and $\varepsilon_{\mathrm{A}}^{\mathrm{H}}$ are the eigenvalues of the lowest unoccupied and highest occupied molecular orbitals respectively.
On the other hand, one may approximate the hardness of an atom as a function of the charge through a Taylor series expansion, 


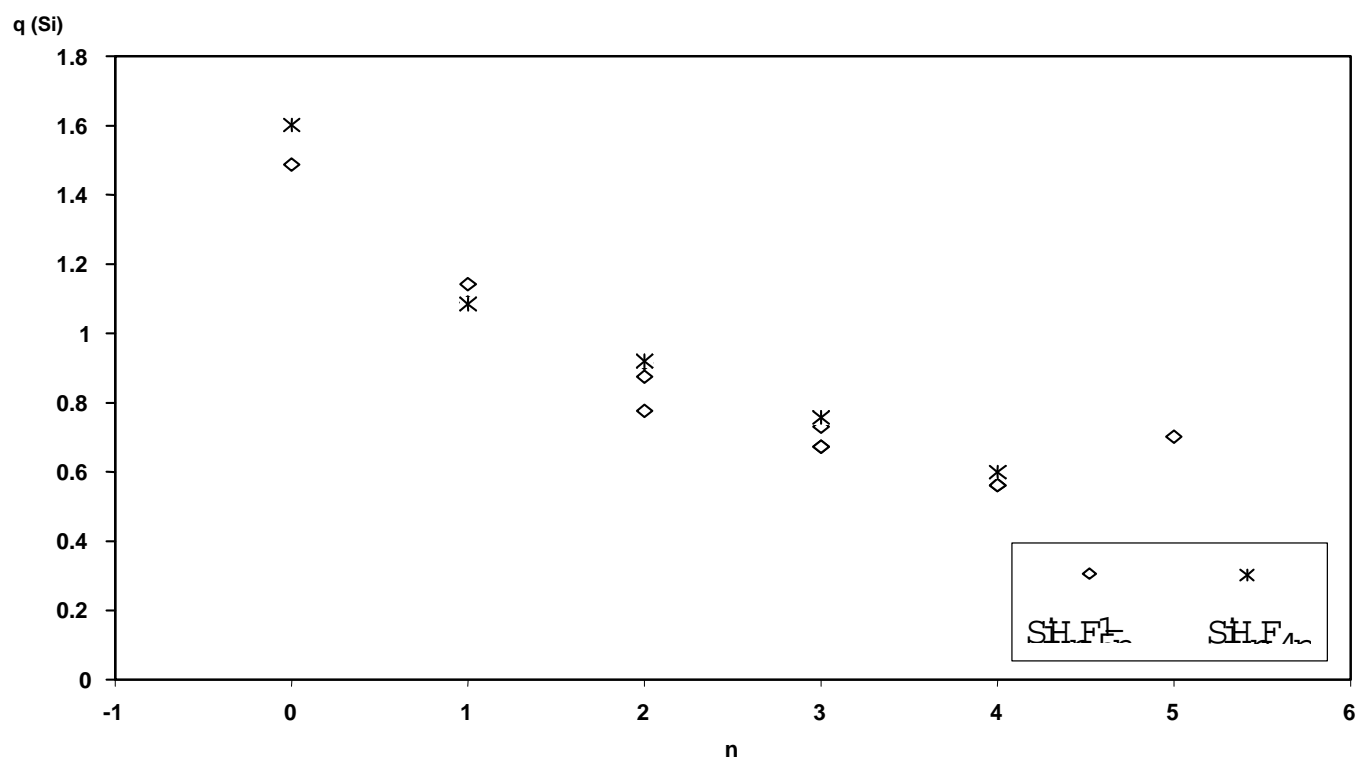

Figure 2. Atomic silicon charge as a function of the number of hydrogen atoms in the molecules $\mathrm{SiH}_{n} \mathrm{~F}_{4-n}$ and $\mathrm{SiH}_{n} \mathrm{~F}_{5-n}^{1-}$ (obtained by a Mülliken population analysis). The silicon charge values are given in a.u.

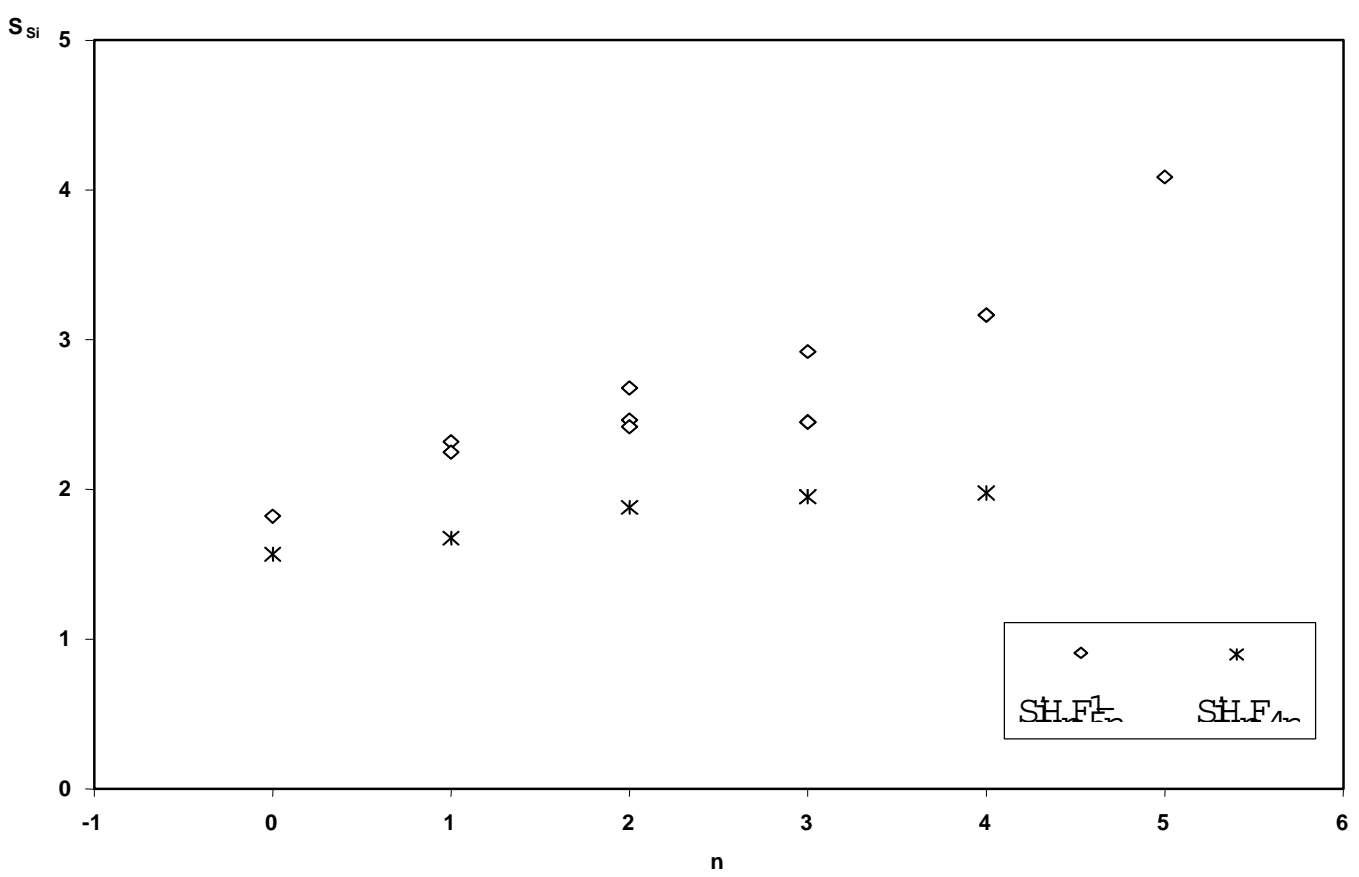

Figure 3. Global softness as a function of the number of hydrogen atoms in the molecules $\mathrm{SiH}_{n} \mathrm{~F}_{4-n}$ and $\mathrm{SiH}_{n} \mathrm{~F}_{5-n}^{1-}$ (obtained by $\left.S=I-A\right)^{-1}$ ). The global softness values are given in a.u. ${ }^{-1}$

$$
\eta_{k}\left(q_{k}\right)=\eta_{k}^{0}-\left.q_{k}\left(\partial \eta_{k} / \partial N_{k}\right)\right|_{N_{k}^{0}}
$$

$$
\left(\frac{\partial \eta_{k}}{\partial N_{k}}\right)_{V} N_{k}^{0}=\left(\frac{\partial^{2} \mu_{k}}{\partial N_{k}^{2}}\right)_{V} N_{k}^{0}=\left(\frac{\partial^{3} E_{k}}{\partial N_{k}^{3}}\right)_{V} N_{k}^{0} \cdot
$$

where $\eta_{k}^{0}$ is the hardness and $N_{k}^{0}$ is the total number of electrons of the isolated neutral atom $k, \mathrm{qk}=N_{k}^{0}-N_{k}$. Note that
Assuming that the hardness of the $k$ th atom in a molecule may be estimated through (9), substitut- 


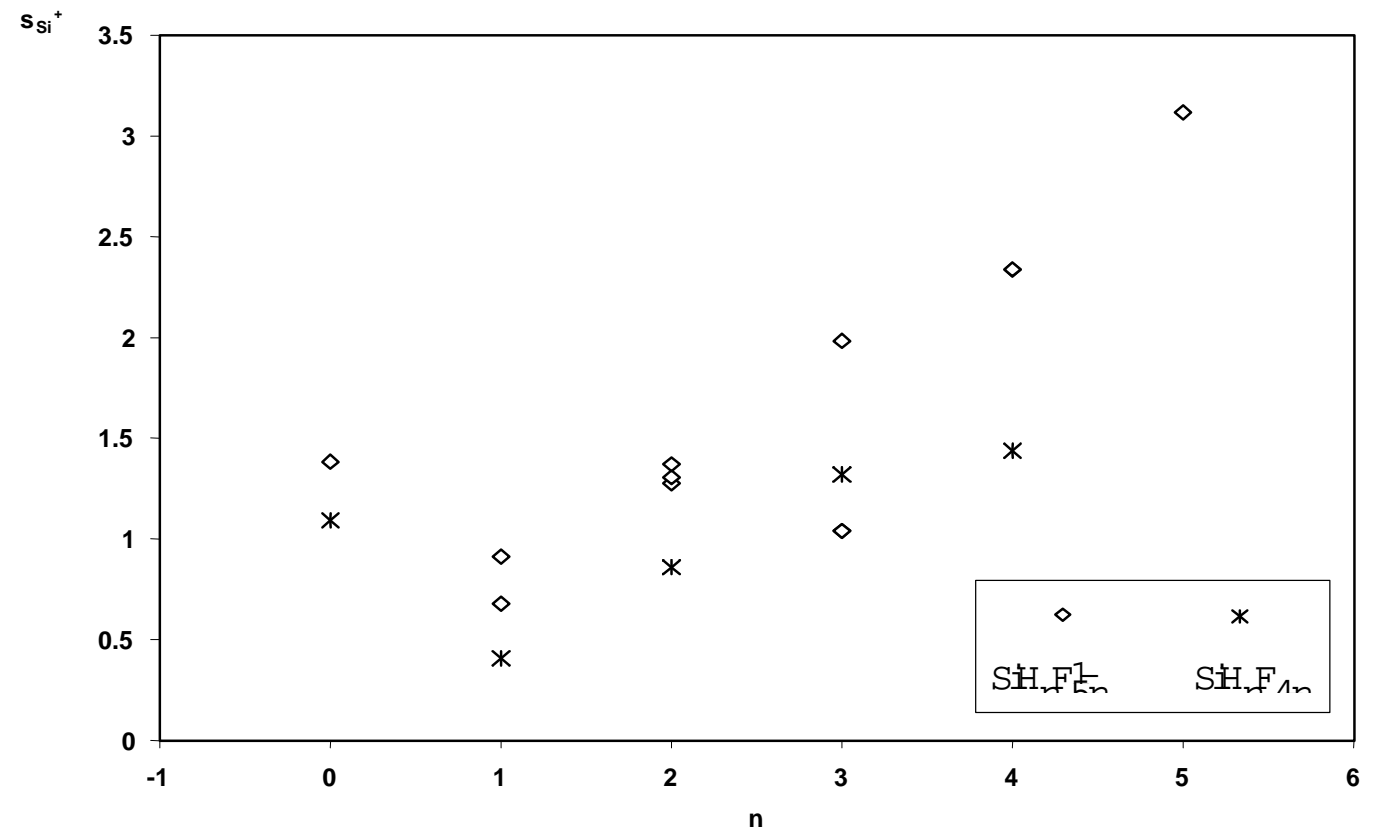

Figure 4. Nucleophilic condensed softness of the silicon atom as a function of the number of hydrogen atoms in the molecules $\mathrm{SiH}_{n} \mathrm{~F}_{4-n}$ and $\mathrm{SiH}_{n} \mathrm{~F}_{5-n}^{1-}\left(\right.$ obtained by $S_{\mathrm{A} k}^{+}=S_{\mathrm{A}}^{+} f_{\mathrm{A} k}^{+}$). The condensed softness values are given in a.u. ${ }^{-1}$

ing in this equation the hardness of an atom as a function of the charge of the $k$ th atom of the molecule A (12), we find that

$$
S_{A k}=\left(\varepsilon_{\mathrm{A}}^{\mathrm{L}}-\varepsilon_{\mathrm{A}}^{\mathrm{H}}\right)^{-1} \frac{\left[\eta_{k}^{0}-\left.q_{k}\left(\partial \eta_{k} / \partial N_{k}\right)\right|_{N_{k}^{0}}\right]^{-1}}{\sum_{k=1}^{k}\left[\eta_{k}^{0}-\left.q_{k}\left(\partial \eta_{k} / \partial N_{k}\right)\right|_{N_{k}^{0}}\right]^{-1}},
$$

where (10) and (11) have been used. This procedure allows us to avoid the calculation of the $\left(N_{\mathrm{A}}+1\right)$ electron molecule, because we one only need the isolated atom values ${ }^{21}$ of $\eta_{k}^{0}$ and $\left(\partial \eta_{k} / \partial N_{k}\right) \downarrow_{N_{k}}$, and the molecular values of $\varepsilon_{\mathrm{A}}^{\mathrm{L}}$ and $\varepsilon_{\mathrm{A}}^{\mathrm{H}}$, and $q_{A k}$ of the $N_{\mathrm{A}}$ electron system.

Thus, we have done ab-initio calculations ${ }^{22}$ of the molecules $\mathrm{SiH}_{n} \mathrm{~F}_{4-n}(0<n<4)$ and $\mathrm{SiH}_{n} \mathrm{~F}_{5-n}^{1-}(0<n<5)$ at the BHHLYP/6-311++G** level (figure 1). In figure 2 we present the behaviour of the charge of the silicon atom in the molecule (obtained from a Mülliken population analysis) as a function of the number of hydrogen atoms $(n)$. We can see that in general the positive charge of the silicon atom is slight higher in the tetracoordinated molecules than in the pentacoordinated molecules.

In figure 3 we present the behaviour of the global softness as a function of $\mathrm{n}$ for the tetracoordinated and the pentacoordinated compounds (calculated by
$\left.S=(I-A)^{-1}\right)$. We can see that the global softness of the pentacoordinated species is larger than the global softness of the tetracoordinated species, and the difference increases as $n$ increases. Since, in general, the larger the values of the softness, the greater the reactivity, these results imply that, globally, the pentacoordinated species shows an enhanced reactivity, and they also imply that the reactivity diminishes when the number of fluorine atoms increases. Calculations of the chemical potential values show that $\mu_{\mathrm{SiH}_{n} n_{n-5}^{1-}}>\mu_{\mathrm{SiH}_{n} \mathrm{~F}_{n-4}}$ and $\mu$ increases when $n$ increases.

Now, from a local point of view, figure 4 shows that the silicon atom is softer in the pentacoordinated species than in the tetracoordinated species (obtained from (7)). These results also imply that the pentacoordinated species shows an enhanced reactivity with respect to the tetracoordinated species. It should be noted that the condensed softness of the silicon atom diminishes when the number of fluorine atoms increases and, therefore, from a local point of view, we may conclude that when $n$ decreases the reactivity decreases.

In figure 5, we present the behaviour of the condensed softness of the silicon atom calculated from (14), we can see that the condensed softness increases as the coordination number and the hydrogen atoms increase. Therefore, the tests that were carried out in 


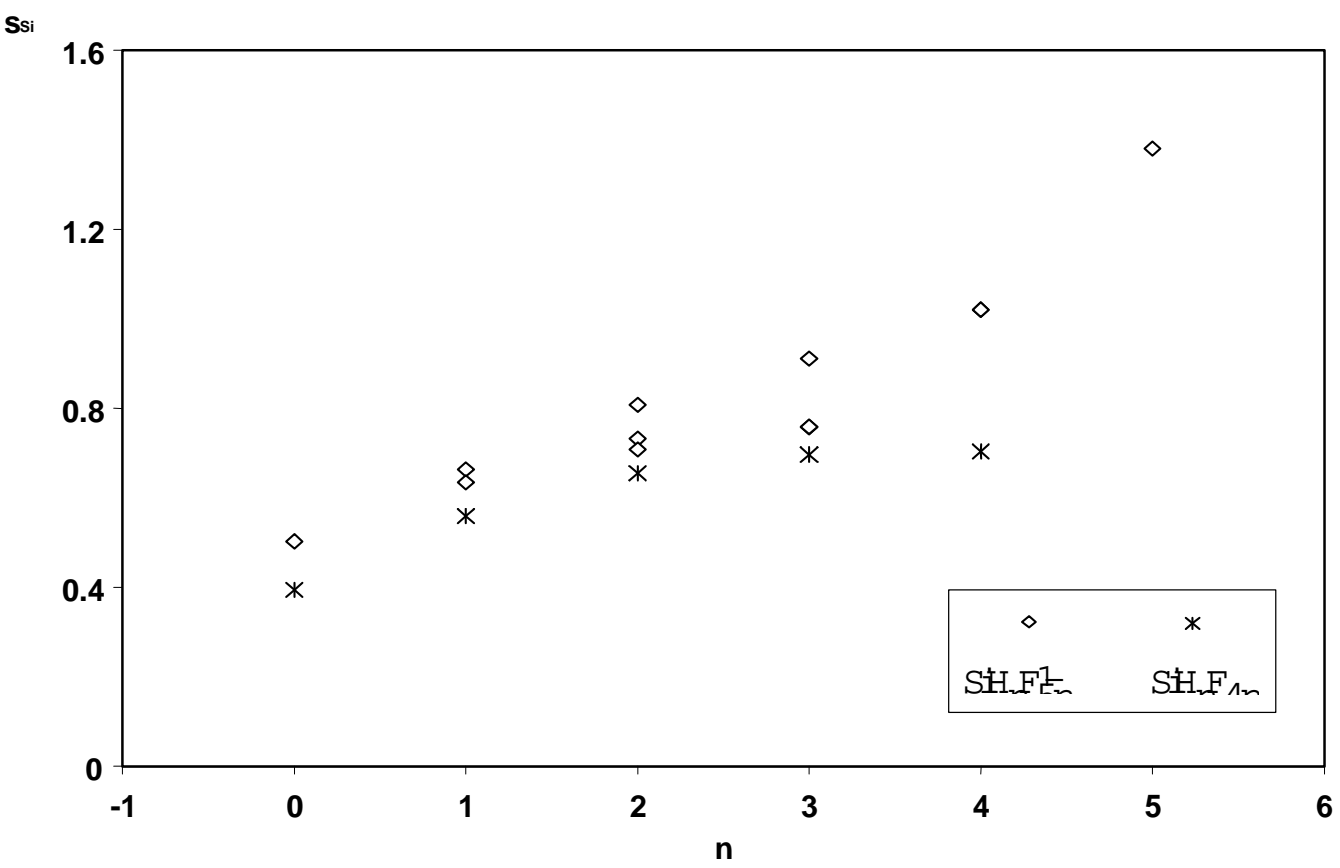

Figure 5. Condensed softness of the silicon atom as a function of the number of hydrogen atoms in the molecules $\mathrm{SiH}_{n} \mathrm{~F}_{4-n}$ and $\mathrm{SiH}_{n} \mathrm{~F}_{5-n}^{1-}$ (obtained by (14)). The condensed softness values are given in a.u. ${ }^{-1}$

$\mathrm{SiH}_{n} \mathrm{~F}_{4-n}$ and $\mathrm{SiHnF}_{5-n}^{1-}$ showed that (14) reproduces qualitatively the same trends as (7). Therefore, if we invoke the local HSAB principle, these results seem to imply that soft nucleophiles preferably react with $\mathrm{SiHnF}_{5-n}^{1-}$ compounds, and hard nucleophiles with $\mathrm{SiH}_{n} \mathrm{~F}_{4-n}$ compounds.

It is important to note that although, in general, the behaviour of the global softness of the systems presented in this work is quite similar to the behaviour of the condensed softness of the silicon center, the subtle differences may be very important to describe the inherent chemical reactivity of these species. Indeed, we believe that the local values provide a better representation of the chemical behaviour of a molecule, and therefore it is predicted that pentacoordinated species will be, in general, more reactive than the tetracoordinated species.

\section{Conclusions}

In summary, it has been shown that the softness of the silicon atom in the molecule seems to be a useful and perhaps unifying concept, to rationalize the inherent reactivity of these chemical species. Thus, we hope that this work will motivate experimental research that may provide information about the role of the condensed softness of the silicon atom as a function of the nucleophile softness, through the study of the interaction between several hypervalent silicon compounds and several nucleophiles. Calculations of the interaction energy through (4) using some examples of soft and hard nucleophiles are in progress.

\section{Acknowledgement}

This work has been supported by a research grant and a Ph D scholarship (M L Romero) from the Consejo Nacional de Ciencia y Tecnología, CONACYTMéxico.

\section{References}

1. Selected reviews dealing with pentacoordinate silicon compounds: (a) Tandura S N, Voronkov M G and Alekseev N V 1986 Top. Curr. Chem. 131 99; (b) Corriu R J P and Young J C 1989. In The chemistry of organic silicon compounds (eds) S Patai and Z Rappoport (Chichester, UK: John Wiley) p. 1241; (c) Sheldrick W S 1989 In The chemistry of organic silicon compounds (eds) S Patai and Z Rappoport (Chichester, UK: John Wiley) p. 227; (d) Chuit C, Corriu R J P, Reye C and Young J C 1993 Chem. 
Rev. 93 1371; (e) Holmes R R 1996 Chem. Rev. 96 927; (f) Kost D, Kalikhman I 1998 In The chemistry of organic silicon compounds (eds) Z Rappoport and Y Apeloig (Chichester, UK: John Wiley) p. 11339; (g) Tacke R, Pülm M and Wagner B 1999 Adv. Organomet. Chem. 44 221; (g) Tacke R, Burschka C, Richter I, Wagner B and Willeke R $2000 \mathrm{~J}$. Am. Chem. Soc. 1228480

2. (a) Corriu R J P, Guerin C, Hennner B J L and Wong Chi Man W W C 1988 Organometallics 7 237; (b) Baybutt P 1975 Mol. Phys. 29389

3. Deiters J A and Holmes R R 1990 J. Am. Chem. Soc. 1127197

4. Pearson R G 1973 Hard and soft acids and bases (ed.) R G Pearson (Philadelphia, PA: Dowden, Hutchinson \& Ross)

5. Parr R G and Pearson R G 1983 J. Am. Chem. Soc. 1131855

6. Pearson R G 1987 J. Chem. Ed. 64561

7. Pearson R G 1990 Coord. Chem. Rev. 100403

8. Chattaraj P K, Lee H and Parr R G 1991 J. Am. Chem. Soc. 1131855

9. Gázquez J L 1993 Chemical hardness: Structure and bonding (ed.) K D Sen (Berlin: Springer) vol. 80, p. 27

10. Gázquez J L and Méndez F 1993 J. Phys. Chem. 98 4591

11. Méndez F and Gázquez J L 1994 J. Am. Chem. Soc. 1169298
12. Méndez F and Gázquez J L 1994 Proc. Indian Acad. Sci. (Chem. Sci.) 106183

13. Parr R G and Yang W 1989 Density functional theory of atoms and molecules (New York: Oxford University Press)

14. (a) Sen K D and Jorgensen C K 1987 Electronegativity: Structure and bonding (Berlin: Springer Verlag); (b) Sen K D 1993 Chemical hardness: Structure and bonding (Berlin: Springer-Verlag) vol. 80

15. Yang W and Parr R G 1985 Proc. Natl. Acad. Sci. USA 826723

16. (a) Pearson R G 1997 Chemical hardness: Applications from molecules to solids (Weinheim: WileyVCH Verlag); (b) Damoun S, Van de Goude G, Méndez F and Geerlings P 1997 J. Phys. Chem. A101 886; (c) Pal S and Chandrakumar K R S $2000 \mathrm{~J}$. Am. Chem. Soc. 122 4145; (d) Chattaraj P K 2001 J. Phys. Chem. A105 511

17. Parr R G and Gázquez J L 1993 J. Phys. Chem. 97 3939

18. Sanderson R T 1951 Science 114670

19. Cioslowski J and Mixon S T 1993 J. Am. Chem. Soc. 1151084

20. Yang W and Mortier W J 1986 J. Am. Chem. Soc. 1085278

21. Fuentealba P and Parr R G 1991 J. Chem. Phys. 94 5559

22. Frisch M J et al 1998 Gaussian 98, revision A.11, Gaussian Inc., Pittsburgh, PA 